\title{
Phasic Temperature Change Patterns Affect Growth and Tuberization in Potatoes
}

\author{
Weixing Cao ${ }^{1}$ and Theodore W. Tibbitts \\ Department of Horticulture, University of Wisconsin, Madison, WI 53706 \\ Additional index words. Solanum tuberosum, dry weight, partitioning, tuber number, tuber size, controlled environment
}

\begin{abstract}
This study determined the responses of potato (Solanum tuberosum L., cv. Norland) plants to various patterns of air temperature changes over different growth periods (phasic temperature changes). In each of two experiments under controlled environments, eight treatments of temperature changes were carried out in two growth rooms maintained at 17 and $22 \mathrm{C}$ and a constant vapor pressure deficit of $0.60 \mathrm{kPa}$ and 14-hour photoperiod. Plants were grown for 63 days after transplanting of tissue culture plantlets in 20 -liter pots containing peat-vermiculite mix. Temperature changes were imposed on days 21 and 42, which were essentially at the beginning of tuber initiation and tuber enlargement, respectively, for this cultivar. Plants were moved between two temperature rooms to obtain eight temperature change patterns: 17-17-17, 17-17-22, 17-22-17, 22-17-17, 17-22-22, 22-17-22, 22-22-17, and 22-22-22C over three 21-day growth periods. At harvest on day 63, total plant dry weight was higher for the treatments beginning with $22 \mathrm{C}$ than for those beginning with $17 \mathrm{C}$, with highest biomass obtained at 22-22-17 and 22-17-17C. Shoot dry weight increased with temperature increases from 17-17-17 to 22-22-22C during the three growth periods. Tuber dry weight was highest with 22-17-17C, and lowest with 17-17-22 and 17-22-22C. With 22-17-17C, both dry weights of stolons and roots were lowest. Total tuber number and number of small tubers $(<2.5 \mathrm{~cm})$ were highest with 17-17-17 and 17-17-22C, and lowest with 17-22-22 and 22-22-22C, whereas number of medium tubers $(2.5-5.0 \mathrm{~cm})$ was highest with $22-17-22 \mathrm{C}$, and number of large tubers $(>5.0 \mathrm{~cm})$ was highest with 22-17-17C. This study indicates that tuber development of potatoes is optimized with a phasic pattern of high temperature during early growth and low temperature during later growth.
\end{abstract}

Temperature is a major factor regulating biomass accumulation and tuber development in potatoes (Bodlaender, 1963; Gregory, 1965; Wheeler et al., 1986; Wolf et al., 1990). When air temperatures were maintained between 12 and 28C under a 12-h photoperiod in a controlled environment, total plant biomass and tuber production in 'Norland' potatoes were greatest at 20C (Wheeler et al., 1986). Both plant growth and tuber yield were slightly depressed at air temperature of $16 \mathrm{C}$ and further depressed at the temperature of $12 \mathrm{C}$. At air temperatures of 24 and $28 \mathrm{C}$, shoot growth was vigorous, but tuberization was inhibited (Wheeler et al., 1986). The inhibitory effect of high temperatures on tuber development has been reported for many potato cultivars and species (Ewing, 1981; Ewing and Struik, 1992; Tibbitts et al., 1992).

Because temperature significantly affects partitioning of photosynthate between shoots and tubers, the optimum temperature for shoot growth differs from that for tuber growth (Gregory, 1965; Wheeler et al., 1986; Wolf et al., 1990). In general, air temperatures $>20 \mathrm{C}$ favor shoot growth and temperatures $<20 \mathrm{C}$ favor tuber growth (Benoit et al., 1983; Ewing, 1981; Gregory, 1965; Moorby and Milthorpe, 1975). Thus, altering temperatures during potato growth might optimize shoot development at an early stage and tuber development at a later stage.

In different commercial production areas, potato plants growing in the field are subject to different patterns of seasonal temperature changes. In northern (i.e., higher) latitudes, temperatures increase during early growth and decrease during later stages. In southern (lower) latitudes where two potato crops are grown each

Received for publication 24 Sept. 1993. Accepted for publication 17 Dec. 1993 Supported by the College of Agricultural and Life Sciences, Univ. of Wisconsin, Madison, and National Aeronautics and Space Administration grant NCC-2-301. The cost of publishing this paper was defrayed in part by the payment of page charges. Under postal regulations, this paper therefore must be hereby marked advertisement solely to indicate this fact.

'Present address: Department of Agronomy, Nanjing Agricultural Univ., Nanjing, Jiangsu 210014, P. R. China. year, seasonal temperature changes have different patterns with each crop. It is suggested that tuber yields may be higher under decreasing temperatures than under increasing temperatures (Werner, 1942). This has been supported by the results from a controlled environment study growing 'Kennebec' potatoes under different temperature conditions with a 12-h photoperiod (McCown and Kass, 1977). However, to establish the effects of phasic temperature changes on plant growth and tuber development of potatoes, additional experiments are needed.

This study was undertaken to investigate dry-matter partitioning and tuberization in potato plants grown under various patterns of air temperature changes over successive growth periods in controlled environments. The information from this study will be useful for optimizing the temperature conditions for maximum tuber production in controlled growing facilities. The results may also have implications for analyzing potato growth in field environments with different seasonal temperature patterns.

\section{Materials and Methods}

Cultural procedures. Two separate experiments were conducted in growth rooms at the Biotron, University of Wisconsin, Madison, with a commercial potato cultivar, Norland. 'Norland' is an early-maturing cultivar, and has been used extensively in our previous environmental studies with potatoes (Wheeler et al., 1986; Tibbitts et al., 1992). This cultivar is maintained with micropropagated stem cuttings grown in sterile agar culture (Hussey and Stacey, 1981; Wheeler et al., 1986).

For both experiments, uniform, single 21-day-old plantlets were transplanted into the centers of 20-liter plastic containers containing 1 commercial peat: 1 vermiculite mix (by volume). The transplants were covered with glass beakers for the first 3 days to minimize transplant shock. Fourteen days after transplanting, the culture containers were filled with an additional 3-cm layer of peat : vermiculite medium so that lower nodes of stems were buried. Plants were watered four times daily with a complete nutrient 
Table 1. Temperature change treatments during three growth periods, and total growing degree days accumulated over the 63-day growth duration. Days 21 and 42 were nearly at the beginning of tuber initiation and tuber enlargement, respectively.

\begin{tabular}{lccc}
\hline \hline & & & $\begin{array}{c}\text { Total } \\
\text { Growth period (C) }\end{array}$ \\
\cline { 1 - 2 } Day 1-21 & Day 22-42 & Day 43-63 & days $(\mathrm{C} \times \mathrm{d})$ \\
\hline 17 & 17 & 17 & 693 \\
17 & 17 & 22 & 798 \\
17 & 22 & 17 & 798 \\
22 & 17 & 17 & 798 \\
17 & 22 & 22 & 903 \\
22 & 17 & 22 & 903 \\
22 & 22 & 17 & 903 \\
22 & 22 & 22 & 1008 \\
\hline
\end{tabular}

solution (Hammer et al., 1978; Wheeler et al., 1986). The duration of each watering was adjusted weekly so that $\approx 50 \%$ of the supplied solution drained through the container after each watering.

Experiment design. In each of two experiments, eight combinations of 17 and 22C air temperatures were maintained during three successive growth periods (Table 1). These two temperatures were selected for their differential promotion of tuber growth (17C) and shoot growth (22C). Constant temperatures were maintained to simplify the experimental conditions. Previously, it was found that 'Norland' potatoes did not significantly benefit from diurnal temperature fluctuations (Bennett et al., 1991). The 63-day duration of this study from transplanting to harvest was divided into three 21-day periods: day 1 to 21 , day 22 to 42 , and day 43 to 63 . Our personal observations have indicated that under temperatures of 18 to 20C 'Norland' plants initiate tubers only after 3 weeks of growth, and will have about 30 small tubers after 6 weeks of growth and significantly enlarged tubers after 8 weeks of growth (Cao and Tibbitts, 1992; Wheeler et al, 1986). Thus, day 21 and day 42 in this study are considered to roughly correspond with the beginning of tuber initiation and significant tuber enlargement, respectively.

For the first 21 days, 16 plants were grown in separate containers in each of the two growth rooms under either constant 17 or $22 \mathrm{C}$ for each experiment. On the 21 st day after transplanting, the twelve most uniform plants in each growth room were retained for the temperature change treatments to provide three replicate plants for each treatment. A maximum of 12 plants could be effectively separated under uniform light condition in a room with minimum plant-to-plant variability. On days 21 and 42, six plants from each growth room were switched to the other growth room, providing eight temperature change patterns over the entire growth duration (Table 1).

The plants in each growth room were arranged in three randomized complete blocks in circular form. Following the first experiment, the temperature regimes of the two growth rooms were switched in order to minimize possible room variation. The whole study was considered as a randomized complete-block design with two blocks for the eight temperature treatments. Each treatment in each block had three plants (subsamples) that exhibited uniform appearance during the entire study.

Environmental conditions. The photosynthetic photon flux (PPF) of $430 \mu \mathrm{mol} \cdot \mathrm{m}^{-2} \cdot \mathrm{s}^{-1}$ at the top of the canopy was provided by cool-white fluorescent lamps for a 14-h period. Relative humidity (RH) was maintained at $68 \%$ and $76 \%$ for the 17 and $22 \mathrm{C}$ air temperatures, respectively, allowing a constant vapor pressure deficit of $0.60 \mathrm{kPa}$ for all temperature treatments. Both tempera- ture and RH were monitored continuously by computer. For the growth rooms at $17 \mathrm{C}$, actual air temperature during the two experiments averaged $17.1 \pm 0.2 \mathrm{C}, \mathrm{RH} 68 \pm 2 \%$, and PPF $425 \pm 29$ $\mu \mathrm{mol} \cdot \mathrm{m}^{-2} \cdot \mathrm{s}^{-1}$. For the other growth rooms at $22 \mathrm{C}$, the levels were $21.9 \pm 0.3 \mathrm{C}, 76 \pm 2 \%$, and $426 \pm 28 \mu \mathrm{mol} \cdot \mathrm{m}^{-2} \cdot \mathrm{s}^{-1}$, respectively. Carbon dioxide levels were ambient at about $350 \mu \mathrm{l} \cdot \mathrm{liter}^{-1}$, but were not continuously monitored in this study.

Harvest and data analysis. Plants were harvested 63 days after transplanting and separated into shoots, tubers, stolons, and roots. Tubers were separated into three size categories: $<2.5 \mathrm{~cm}, 2.5-5.0$ $\mathrm{cm}$, and $>5.0 \mathrm{~cm}$ in diameter, and the number of tubers in each category was determined. A tuber was counted when it was larger than twice the diameter of the stolon. All plant materials were dried at $70 \mathrm{C}$ for 3 days and dry weights were obtained for the different plant parts.

An analysis of variance (ANOVA) was conducted for each of the measurements with eight temperature change treatments in two duplicated experiment runs (blocks). Each value used in the ANOVA was an average from the three plants for each treatment in each experiment run. Duncan's multiple range test was used to separate treatment means at $P=0.05$.

Total growing degree days accumulated over the 63-day experiment period were calculated for the different temperature change treatments using a base temperature of 6C (Bodlaender, 1963; Moorby and Milthorpe, 1975). Correlation analyses were made between the growing degree days and the separate dry weights of tubers and shoots.

\section{Results}

Plant dry weight and partitioning. Total plant growth was significantly different for the eight patterns of temperature changes over three growth periods. The total dry weight per plant was highest with the 22-22-17C and then 22-17-17C treatments (Table 2). All treatments with $22 \mathrm{C}$ during the first period had higher total plant dry weights than those beginning with $17 \mathrm{C}$. Thus, relatively high temperatures during the early vegetative period promoted growth of whole potato plants.

The dry weights of shoots and tubers responded to temperature change treatments differently. Shoot dry weight increased with the increasing amount of time at $22 \mathrm{C}$ compared to constant $17 \mathrm{C}$ (Table 2 ). Comparing the treatments with the $22 \mathrm{C}$ during one of the three

Table 2. Dry weights of whole and different parts of potato plants grown with various temperature change patterns.

\begin{tabular}{ccccll}
\hline \hline \multirow{2}{*}{$\begin{array}{c}\text { Treatment } \\
(\mathrm{C})\end{array}$} & Total plant & \multicolumn{5}{c}{ Plant parts } \\
\cline { 3 - 6 } & & & \multicolumn{5}{c}{ Shoot } & Tuber & Stolon & Root \\
\hline $17-17-17$ & $196.7 \mathrm{~d}^{\mathrm{y}}$ & $116.6 \mathrm{f}$ & $74.9 \mathrm{c}$ & $2.87 \mathrm{~d}$ & $2.33 \mathrm{~d}$ \\
$17-17-22$ & $190.6 \mathrm{~d}$ & $147.2 \mathrm{~cd}$ & $36.6 \mathrm{f}$ & $4.04 \mathrm{ab}$ & $2.71 \mathrm{~d}$ \\
$17-22-17$ & $202.6 \mathrm{~d}$ & $140.9 \mathrm{de}$ & $53.8 \mathrm{e}$ & $4.25 \mathrm{a}$ & $3.62 \mathrm{bc}$ \\
$22-17-17$ & $258.5 \mathrm{ab}$ & $132.7 \mathrm{e}$ & $120.5 \mathrm{a}$ & $2.85 \mathrm{~d}$ & $2.46 \mathrm{~d}$ \\
$17-22-22$ & $205.3 \mathrm{~d}$ & $164.2 \mathrm{~b}$ & $33.9 \mathrm{f}$ & $3.60 \mathrm{bc}$ & $3.57 \mathrm{bc}$ \\
$22-17-22$ & $234.2 \mathrm{c}$ & $157.2 \mathrm{bc}$ & $70.5 \mathrm{~cd}$ & $3.37 \mathrm{c}$ & $3.18 \mathrm{c}$ \\
$22-22-17$ & $261.6 \mathrm{a}$ & $154.3 \mathrm{bc}$ & $99.5 \mathrm{~b}$ & $3.77 \mathrm{abc}$ & $4.03 \mathrm{ab}$ \\
$22-22-22$ & $243.5 \mathrm{bc}$ & $176.3 \mathrm{a}$ & $59.1 \mathrm{de}$ & $3.99 \mathrm{ab}$ & $4.22 \mathrm{a}$ \\
$P$ value $^{\mathrm{z}}$ & 0.0001 & 0.0001 & 0.0001 & 0.0019 & 0.0002 \\
$\mathrm{CV}^{\mathrm{z}}$ & 0.03 & 0.03 & 0.09 & 0.06 & 0.06
\end{tabular}

${ }^{\mathrm{z}}$ Probability of a significance $\mathrm{F}$ value for treatments, and coefficient of variation $(\mathrm{CV})$.

'Mean separation in each column by the Duncan's multiple range test at $P=0.05$. 
growth periods, shoot growth tended to increase with the $22 \mathrm{C}$ during later growth period (highest shoot dry weight at 17-17-22C). This temperature effect on shoot growth was accompanied by reduced tuber growth in these plants.

Tuber dry weight varied among the eight treatments more than shoot dry weight (Table 2). Tuber dry weight was highest with 22-17-17C, and lowest with 17-22-22 and 17-17-22C. Tuber dry weight with $22-17-17 \mathrm{C}$ was at least $20 \%$ higher than that of any other treatment and $60 \%$ higher than with constant 17 or $22 \mathrm{C}$. The high to low temperature pattern significantly favored tuber growth.

Dry weights of stolons and roots were small compared to those for shoots and tubers (Table 2). Stolon dry weight was highest with 17-22-17, whereas root dry weight was highest with 22-22-22C. There were no consistent relationships between stolon and root mass or between stolon/root mass and tuber production, yet the treatment with the greatest tuber mass (22-17-17C) had the lowest dry weights of stolons and roots.

Tuber number and size distribution. Total tuber number varied substantially with the different patterns of temperature changes. Tuber number was highest with 17-17-17 and 17-17-22C, and lowest with 17-22-22 and 22-22-22C (Table 3). Thus, tuber initiation was depressed most when the temperature was $22 \mathrm{C}$ from the beginning of tuber initiation, but was not affected by a temperature increase delayed until the beginning of tuber enlargement. It is noted that tuber dry weights were lowest with both 17-17-22 and 17-22-22C treatments (Table 2), yet tuber number was highest (70 tubers) with 17-17-22C and lowest (33 tubers) with 17-22-22C. Thus, tuber initiation and tuber enlargement responded differently to the temperature change patterns during growth.

Small tubers $(<2.5 \mathrm{~cm})$ accounted for the majority of tubers in most treatments and were closely related to the total number of tubers (Table 3). However, number of medium $(2.5-5.0 \mathrm{~cm})$ and large $(>5.0 \mathrm{~cm})$ tubers exhibited different responses to the temperature treatments as compared to the small tubers. The medium tubers made up $20 \%$ to $50 \%$ of the total tuber number. The number of medium tubers was highest with 22-17-22C and lowest with $22-22-17,22-22-22$, and $17-22-22$ C. Less than $15 \%$ of the total tubers were in the large size category for any treatment. The number of large tubers was consistently higher with a high to low temperature pattern, such as $22-17-17$ or $22-22-17 \mathrm{C}$, and lower with a low to high temperature pattern, such as 17-17-22 or $17-22-22 \mathrm{C}$. This variation in number of large tubers was closely related to total tuber dry weights for the different treatments.

\section{Discussion}

Tuber growth was greater with an air temperature of $17 \mathrm{C}$ than with $22 \mathrm{C}$, whereas shoot growth was greater at $22 \mathrm{C}$ than at $17 \mathrm{C}$. These differential effects of temperatures on tubers and shoots are consistent with previous reports (Moorby and Milthorpe, 1975; Wheeler et al., 1986). This study also demonstrates that changes in temperature patterns during growth can significantly increase or decrease tuber production of potatoes. Highest tuber dry weights were obtained with early high temperature followed by low temperature as in the 22-17-17 and 22-22-17C treatments, whereas the lowest tuber dry weight was produced with early low temperature followed by high temperature, e.g., 17-22-22 and 17-17-22C. Apparently, the $22 \mathrm{C}$ temperature during the initial vegetative period produced a rapid establishment of foliar canopy and thus promoted plant growth, whereas the 17C during later stages maximized tuber growth with sufficient support of leaf assimilates. Thus, potatoes can tolerate or even benefit from warm temperatures during early growth. However, cool temperatures
Table 3. Total number of tubers per plant and separation into different size categories for potatoes grown with various temperature change patterns.

\begin{tabular}{lcccl}
\hline \hline & & \multicolumn{3}{c}{ Size category $(\mathrm{cm})$} \\
\cline { 3 - 5 } Treatment & Total tubers & \multicolumn{3}{c}{ no./plant } \\
\hline & & $48.5-5.0$ & $>5.0$ \\
$17-17-17$ & $75.2 \mathrm{a}^{\mathrm{y}}$ & $51.0 \mathrm{a}$ & $23.7 \mathrm{~b}$ & $2.7 \mathrm{c}$ \\
$17-17-22$ & $70.0 \mathrm{ab}$ & $31.8 \mathrm{~b}$ & $20.7 \mathrm{cc}$ & $0.0 \mathrm{~d}$ \\
$17-22-17$ & $53.0 \mathrm{c}$ & $30.3 \mathrm{~b}$ & $20.8 \mathrm{bc}$ & $8.5 \mathrm{a}$ \\
$22-17-17$ & $59.7 \mathrm{bc}$ & $19.3 \mathrm{c}$ & $13.8 \mathrm{~d}$ & $0.2 \mathrm{~d}$ \\
$17-22-22$ & $33.3 \mathrm{e}$ & $30.5 \mathrm{~b}$ & $29.5 \mathrm{a}$ & $1.5 \mathrm{~cd}$ \\
$22-17-22$ & $61.5 \mathrm{bc}$ & $33.2 \mathrm{~b}$ & $10.8 \mathrm{~d}$ & $6.8 \mathrm{~b}$ \\
$22-22-17$ & $50.8 \mathrm{~cd}$ & $25.2 \mathrm{bc}$ & $12.7 \mathrm{~d}$ & $2.2 \mathrm{c}$ \\
$22-22-22$ & $40.0 \mathrm{de}$ & 0.0001 & 0.0001 & 0.0002 \\
$P$ value $^{\mathrm{z}}$ & 0.0001 & 0.10 & 0.10 & 0.23 \\
CV $^{\mathrm{z}}$ & 0.09 & &
\end{tabular}

$\overline{{ }^{2} \text { Probability of a significance } \mathrm{F} \text { value for treatments, and coefficient of }}$ variation $(\mathrm{CV})$.

yMean separation in each column by the Duncan's multiple range test at $P=0.05$.

will be of particular importance during tuber growth. This is essentially consistent with a previous report that a high to cool temperature pattern promoted tuber yield (McCown and Kass, 1977).

The highest tuber dry weight obtained with $22-17-17 \mathrm{C}$ was $60 \%$ greater than that obtained at constant $17 \mathrm{C}$ and $100 \%$ higher than at constant $22 \mathrm{C}$. According to a previous study (Wheeler et al., 1986), it might be argued that an optimum temperature of $20 \mathrm{C}$ constant could have provided significantly higher tuber yields than the $22-17-17 \mathrm{C}$ in this study. However, in that study maximum tuber mass obtained at constant 20C was only $6 \%$ higher than at constant 16C (Wheeler et al., 1986). These data suggest that tuber productivity with a high to low temperature pattern will be potentially greater than at any constant temperature. This information will be particularly useful for optimizing temperature conditions for maximum tuber productivity in controlled growing facilities.

The temperature of $17 \mathrm{C}$ has been documented as nearly optimal for tuber formation in potatoes (Gregory, 1965). In this study, tuber initiation and tuber enlargement exhibited different responses to the temperature conditions during plant growth. Total number of tubers was highest at $17 \mathrm{C}$ during both vegetative growth and tuber initiation stages (17-17-17 and 17-17-22C). Thus, to obtain a maximum number of tubers, relatively low temperatures are required even from the beginning of the plant growth cycle. In contrast, the number of large tubers was highest with 22-17-17 and 22-22-17C. This high-low temperature pattern was even more important for tuber sizing than a constant temperature level during a growth cycle such as 17-17-17C.

Although total tuber number was highest at 17-17-17 and 17-17-22C, stolon mass was much lower at 17-17-17C than at 17-17-22C. Thus, amount of stolon mass does not seem to be important for tuber initiation. However, highest total tuber numbers in these two treatments did not produce highest tuber dry weights. Rather, tuber dry weight was related to the number of large size tubers as obtained with 22-17-17 and 22-22-17C. It has been documented that tuber size is partly controlled by stolon characteristics including the date of initiation and their position and size (Struik, et al., 1991). Thus tuber size can be partly determined before tuberization, and then affected by tuber-specific factors such as the position and activity of the tubers. However, the data in the present study indicate that stolon characteristics may not 
be crucial for tuber sizing. Ewing (1981) has also shown with leaf cuttings that greatest tuberization is with minimal stolon growth.

Previous studies have demonstrated that increased temperatures not only increase partitioning into shoots (Wheeler et al., 1986; Wolf et al., 1990), but also increase partitioning into combined stolons and roots (Wolf et al., 1990). This study indicates that a temperature increase from 17 to $22 \mathrm{C}$ affected the partitioning into the roots more than partitioning into stolons. However, partitioning into both stolons and roots was higher with 17-22-17C than with constant $22 \mathrm{C}$, but lower with $22-17-17 \mathrm{C}$ than with constant $17 \mathrm{C}$. Thus, the patterns of temperature changes affected dry matter partitioning into all plant parts including stolons and roots. However, the combined stolon and root mass in this study accounted for only $2 \%-4 \%$ of total plant dry weight; thus, the variation in stolons and roots due to temperature has a negligible effect on total quantity of plant biomass.

Shoot dry weight (Table 2) was closely correlated to the number of growing degree days accumulated for each treatment (Table 1) with a $R$ of 0.96 . However, tuber dry weight was not related to growing degree days $(R=0.14)$, and instead were regulated by temperature change patterns during growth periods. Tuber dry weight varied three times with different temperature patterns for the same number of growing degree days. Thus, total plant dry weight also was not closely correlated with growing degree days. This suggests that temperature change patterns during the growing season under various production environments may affect tuber development more than the growing degree days accumulated. The lack of correlation between tuber yield and growing degree days was also found in a previous study involving different temperature combinations during growth (McCown and Kass, 1977).

Growing degree day, or thermal time concept, has been used to predict tuber formation (Jefferies and Mackerron, 1987; Manrique and Hodges, 1989) and dry-matter production and partitioning in simulating potato growth under different growing environments (Ingram and McCloud, 1984; van Heemst, 1986). Our study suggests that to accurately predict potato response to temperature, patterns of temperature changes during growth need to be considered to modify growing degree-day predictions for tuber productivity.

\section{Literature Cited}

Bennett, S.M., T.W. Tibbitts, and W. Cao. 1991. Diurnal temperature fluctuation effects on potatoes grown with 12-h photoperiods. Amer. Potato J. 68:81-86.
Benoit, G.R., C.D. Stanley, W.J. Grant, and D.B. Torrey. 1983. Potato top growth as influenced by temperatures. Amer. Potato. J. 60:489-501.

Bodlaender, K.B.A. 1963. Influence of temperature, radiation and photoperiod on development and yield, p. 199-210. In: J.D. Ivins and F.L. Milthorpe (eds.). The growth of the potato. Butterworths, U.K.

Cao, W. and T.W. Tibbitts. 1992. Temperature cycling periods affect growth and tuberization in potatoes under continuous irradiation. HortScience 27:344-345.

Ewing, E.E. 1981. Heat stress and the tuberization stimulus. Amer. Potato. J. 58:31-49.

Ewing, E.E. and P.C. Struik. 1992. Tuber formation in potato: induction, initiation, and growth. Hort. Rev. 14:89-198.

Gregory, L.E. 1965. Physiology of tuberization in plants. Encyclopedia Plant Physiol. 15:1328-1354.

Hammer, P.A., T.W. Tibbitts, R.W. Langhans, and J.C. McFarlane. 1978. Baseline growth studies of 'Grand Rapids' lettuce in controlled environments. J. Amer. Soc. Hort. Sci. 103:649-655.

Hussey, G. and N.J. Stacey. 1981. In vitro propagation of potato (Solanum tuberosum L.). Ann. Bot. 48:787-796.

Ingram, K.T. and D.E. McCloud. 1984. Simulation of potato crop growth and development. Crop Sci. 24:21-27.

Jefferies, R.H. and D.K.L. Mackerron. 1987. Thermal time as a non-destructive method of estimating tuber initiation in potatoes. J. Agr. Sci. 108:249-252.

McCown, B.H. and I. Kass. 1977. Effect of production temperature of seed potatoes on subsequent yielding potential. Amer. Potato J. 54:277287.

Manrique, L.A. and T. Hodges. 1989. Estimation of tuber initiation in potatoes grown in tropical environments based on different methods of computing thermal time. Amer. Potato J. 66:425-437.

Moorby, J. and F.L. Milthorpe. 1975. Potato, p. 225-257. In: L.T. Evans (ed.). Crop physiology. Cambridge Univ. Press, U.K.

Struik, P.S., D. Vreugdenhil, A.J. Haverkort, C.B. Bus, and R. Dankert. 1991. Possible mechanisms of size hierarchy among tubers on one stem of a potato (Solanum tuberosum L.) plant. Potato Res. 34:187-203.

Tibbitts, T.W., W. Cao, and S.M. Bennett. 1992. Utilization of potatoes for life support in space. V. Evaluation of cultivars in response to continuous light and high temperature. Amer. Potato. J. 69:229-237.

van Heemst, H.D.J. 1986. The distribution of dry matter during growth of a potato crop. Potato Res. 29:55-66.

Werner, H.O. 1942. Relative response of several varieties of potatoes to progressively changing temperatures and photoperiods controlled to simulate 'northern' and 'southern' conditions. Amer. Potato J. 19:3140.

Wheeler, R.M., K.L. Steffen, T.W. Tibbitts, and J.P. Palta. 1986. Utilization of potatoes for life support systems. II. The effects of temperature under 24-h and 12-h photoperiods. Amer. Potato. J. 63: 639-647.

Wolf, S., A. Marani, and J. Rudich. 1990. Effects of temperature and photoperiod on assimilate partitioning in potato plants. Ann. Bot. 66:513-520. 